\title{
Comparison between unilateral PNIF and rhinomanometry in healthy and obstructed noses*
}

\author{
Giancarlo Ottaviano', Valerie J. Lund², Ennio Nardello', Bruno Scarpa, \\ Giuliana Frasson', Alberto Staffieri', Glenis K. Scadding² \\ Rhinology 52: 25-30, 2014 \\ DOI:10.4193/Rhino13.037 \\ ' Department of Neurosciences, Otolaryngology Section, University of Padova, Padova, Italy \\ *Received for publication: \\ 2 Ear Institute, University College London, London, United Kingdom \\ April 28, 2013 \\ ${ }^{3}$ Department of Statistical Sciences, University of Padova, Padova, Italy \\ Accepted: July 17, 2013
}

\begin{abstract}
Aims: Peak Nasal Inspiratory Flow (PNIF) is an easy method to assess nasal patency. Normative unilateral PNIF data in adults have been proposed. The study purpose was to compare PNIF and unilateral PNIF values to total and unilateral nasal resistances measured by anterior active rhinomanometry (AAR) in subjects with and without nasal obstruction to see whether unilateral PNIF is sensitive to detect nasal obstruction.
\end{abstract}

Methods and Results: Measurements of PNIF, unilateral PNIF and AAR were performed in 125 volunteers. Seventy of them were healthy subjects not complaining of nasal symptoms and entered into the study as the 'normal' group. The other group consisted of fifty-five symptomatic subjects.

Data were analysed to show the correlation between PNIF, unilateral PNIF and nasal resistances. The ability of PNIF and AAR in predicting pathologies were compared by receiver operating characteristic $(\mathrm{ROC})$ analysis indicating that PNIF and AAR have a similar and significant power to discriminate pathologic from healthy subjects.

Conclusion: The measurement of unilateral PNIF could be a helpful method to support the diagnosis of nasal blockage also in those cases with single nostril obstruction, but, in cases of doubt, AAR should also be performed to improve diagnostic accuracy.

Key words: Peak Nasal Inspiratory Flow, unilateral Peak Nasal Inspiratory Flow, Anterior Active Rhinomanometry, nasal patency, ROC curves

\section{Introduction}

Nasal airway obstruction is a common problem in ENT practice and has been shown to correlate with decreased quality of life as a result of, amongst others, decreased quality of sleep, (chronic) rhinosinusitis, otitis media and asthma ${ }^{(1)}$.

The measurement of nasal patency is of considerable importance for rhinologists and respiratory physiologists. Rhinomanometry $(\mathrm{RM})$ is still regarded as gold standard for the measurement of nasal airway resistances ${ }^{(2)}$. Peak nasal inspiratory flow (PNIF) has been shown to be reproducible in the evaluation of nasal airway obstruction and as good an indication of objective nasal patency as formal RM ${ }^{(3)}$. Furthermore, PNIF is a cheap, simple and easily performed method to assess nasal patency and it is suitable for serial measurements and for home use ${ }^{(4)}$, even in paediatric population ${ }^{(5)}$. Although in the recent past, normal PNIF values in adults have been published ${ }^{(6,7)}$ and the fact that patients who have objective evidence of blockage get better results from septal surgery than those who do not ${ }^{(4)}$, the majority of septal and turbinate surgery is still undertaken around the world without any objective confirmation of genuine mechanical obstruction ${ }^{(8)}$. 
PNIF has traditionally been considered not useful in the diagnosis of unilateral nasal diseases ${ }^{(9)}$, but in 2012 a pilot study from Ottaviano and coauthors tried to establish unilateral PNIF baseline normal values in adult normal subjects opening up the possibility of using a simple method to assess unilateral nasal obstruction. The authors concluded that the measurement of unilateral PNIF could be useful to assess single nostril patency and to compare it with total nasal patency, but recommended more studies to confirm those results in a larger series of healthy volunteers and obstructed patients ${ }^{(10)}$.

The aim of the present study was to compare PNIF and unilateral PNIF values to total and unilateral nasal resistances measured by anterior active rhinomanometry (AAR) in patients with and without nasal obstruction to know whether unilateral PNIF is sensitive to detect various degrees of nasal obstruction.

\section{Materials and methods}

\section{Patients}

A population of 125 subjects ranging from 20 to 80 years old was recruited at the Department of Otolaryngology, Head and Neck Surgery of Padova University. The population consisted of two groups: one group was composed of 70 healthy volunteers who had no nasal diseases and were recruited from students, colleagues, nurses, patients attending for problems other than the nose and from patients' relatives; the other group was composed of 55 symptomatic subjects attending the Rhinologic Outpatient Clinic. All of them complained of nasal obstruction and suffered from nasal diseases (i.e: allergic rhinitis, septal deviations, non-allergic chronic rhinosinusitis).

The present investigation was conducted in accordance with the 1996 Helsinki Declaration and was approved by an internal ENT committee. Written informed consent was obtained from all participants before undertaking any study-related procedures.

\section{Questionaire}

On enrolment into the study, all subjects were asked to complete a SNOT 22 questionnaire ${ }^{(11)}$. The healthy volunteers were also asked if they were experiencing nasal blockage, if they were smokers, asthmatic or had undergone any previous surgery on the nose and paranasal sinuses. All those subjects with a score $<1$ on the SNOT 22, who were non-smokers, non-asthmatic, without any previous sinonasal surgery and did not take oral contraceptives nor $\beta$-blockers or corticosteroid, entered into the study as part of the healthy'normal' group.

\section{PNIF and AAR measurments}

A portable Youlten peak flow meter (Clement Clark International) was used for the measurement of PNIF. Unilateral PNIF (IPNIF and rPNIF) were also studied and all measurements were conducted as previously reported ${ }^{(6,7,10)}$.

Nasal patency was also evaluated using AAR (Rhinolab, Rendsburg, Germany) as previously described ${ }^{(12,13)}$. For the present study, as it was more related to nasal patency ${ }^{(14)}$, only inspiratory nasal resistances were considered and AAR values were expressed in Pascal (Pa).

\section{Statistical analyses}

Fisher's exact test was used to compare the occurrence of a mean SNOT22 value $\geq 1$ between the two groups and the Bravais-Pearson correlation test was used to measure the association between PNIF and AAR in each group of study, for males and females together and separately. The same test was also used to evaluate in the pathologic group the correlation between PNIF and AAR with nasal obstruction subjectively assessed by mean of the SNOT22. P-values have been calculated for all tests, and $5 \%$ was considered as the critical level of significance.

Receiver operating characteristic (ROC) curves were calculated and used to compare the ability of PNIF and AAR in predicting pathologies. To consider joint effects between AAR and PNIF, respectively, with other variables available (gender, age and height), a logistic model has been chosen (after considering also other different flexible models which, however, did not fit the data better). A stepwise procedure based on the Akaike information criterion (AIC) ${ }^{(15)}$ selected the significant variables for prediction of pathologic patients. ROC curves have been calculated to compare sensibility and specificity between models including AAR and those including PNIF. Delong confidence interval were computed to include uncertainty in the estimate of the area under ROC curves ${ }^{(16)}$.

The R: a language and environment for statistical computing ( $R$ Foundation for Statistical Computing, Vienna, Austria) was used for all analyses.

\section{Results}

Mean and standard deviation (SD) of nasal flows and nasal resistances of the healthy group are not shown in the present paper as PNIF, IPNIF, rPNIF and AAR, IAAR, rAAR values were in line with those already available in literature.

Mean and SD of PNIF, IPNIF, rPNIF and AAR, IAAR, rAAR results of the pathologic group are shown in Table 1 separately for males and females.

When considering either the healthy or the pathological population separately, PNIF, IPNIF, rPNIF showed in both of them a significant negative correlation with respectively AAR, IAAR, rAAR (Figure 1, Figure 2; Table 2). 

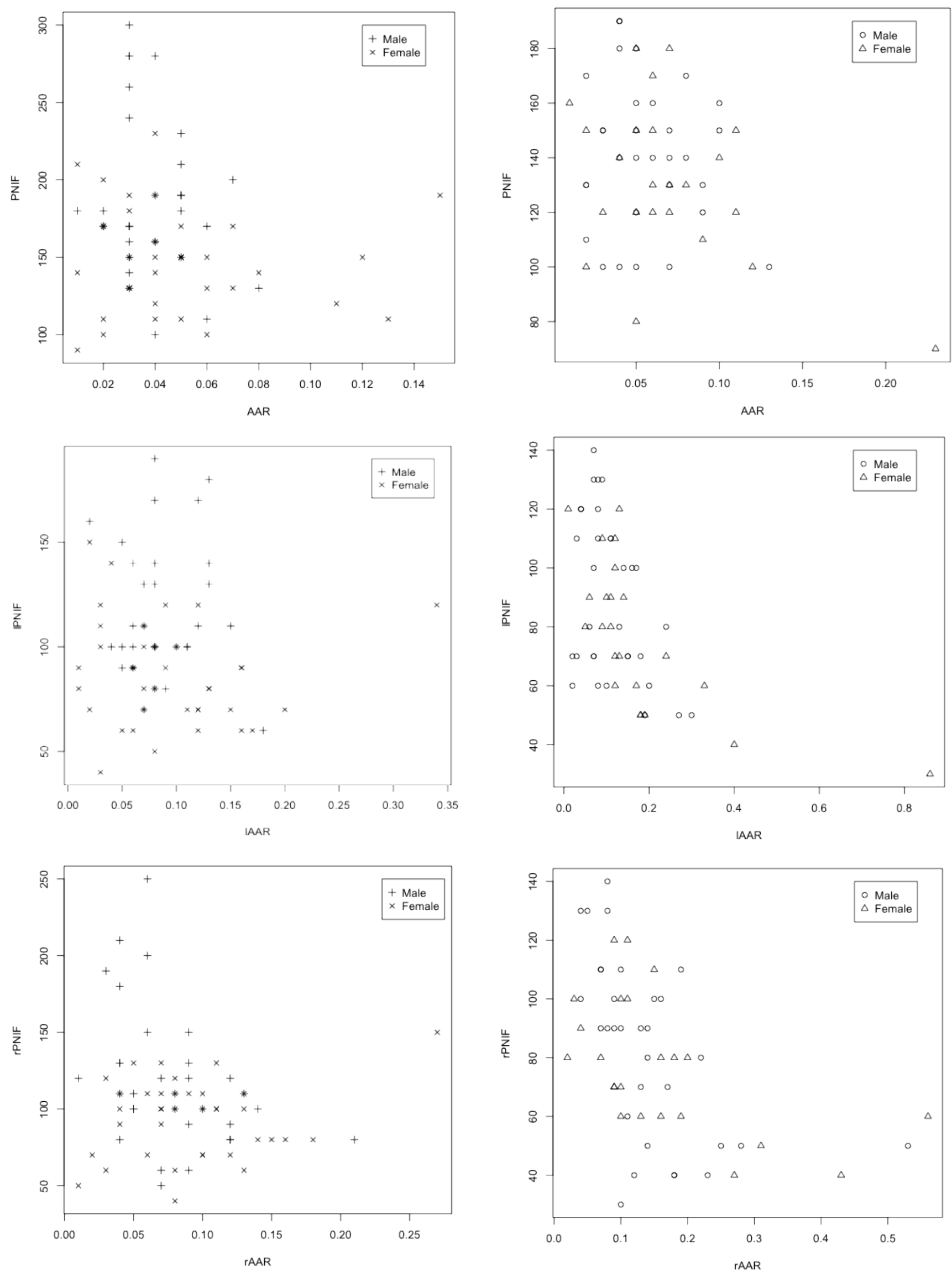

Figure 1. PNIF, IPNIF, rPNIF against respectively AAR, IAAR, rAAR for male and female subjects of the healthy group.

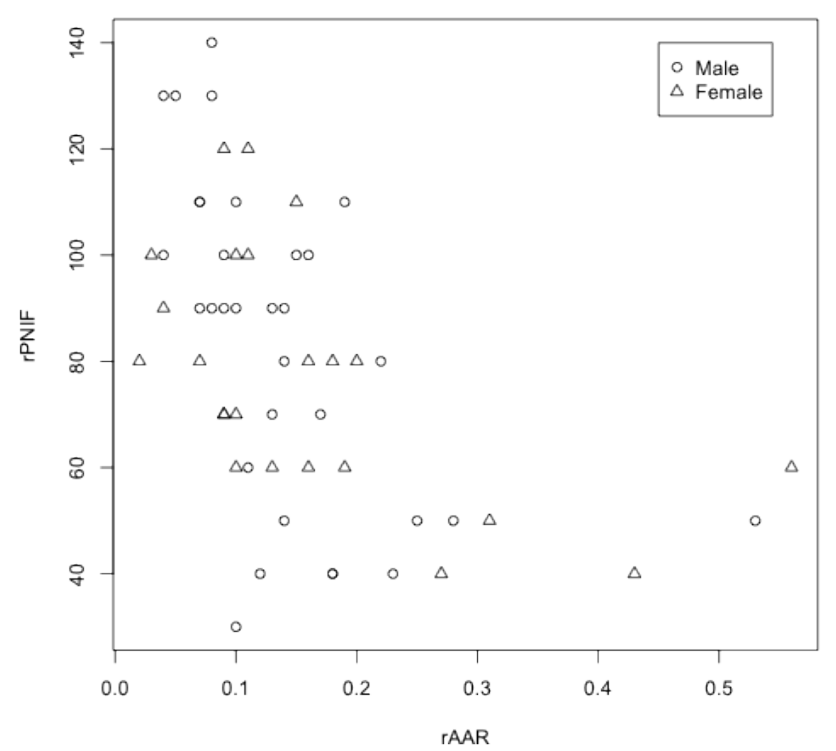

Figure 2. PNIF, IPNIF, rPNIF against respectively AAR, IAAR, rAAR for male and female subjects of the pathologic group. 
Table 1. Mean age, height and nasal function results in males and females of the pathologic group.

\begin{tabular}{|c|c|c|c|c|c|c|}
\hline \multirow[b]{2}{*}{ Variable } & \multicolumn{3}{|c|}{ Males $(n=32)$} & \multicolumn{3}{|c|}{ Females $(n=23$ ) } \\
\hline & Mean & SD & Range & Mean & SD & Range \\
\hline Age & 40.3 & 18.4 & $20-73$ & 44.0 & 17.6 & $20-77$ \\
\hline Height & 177.9 & 5.5 & $166-190$ & 165.2 & 5.6 & $152-173$ \\
\hline IPNIF(L/min) & 89.1 & 27.6 & $50-140$ & 77.0 & 25.1 & $30-120$ \\
\hline rPNIF (L/min) & 83.1 & 30.9 & $30-140$ & 77.4 & 23.0 & $40-120$ \\
\hline PNIF (L/min) & 142.8 & 27.9 & $100-190$ & 131.3 & 28.7 & $70-180$ \\
\hline IAAR (Pa*sec/ml) & 0.11 & 0.08 & $0.02-0.30$ & 0.18 & 0.17 & $0.01-0.86$ \\
\hline rAAR (Pa*sec/ml) & 0.14 & 0.09 & $0.04-0.53$ & 0.16 & 0.13 & $0.02-0.56$ \\
\hline AAR $\left(\mathrm{Pa}^{*}\right.$ sec/ml) & 0.06 & 0.03 & $0.02-0.13$ & 0.07 & 0.05 & $0.01-0.23$ \\
\hline
\end{tabular}

Table 2. Correlations between AAR, rAAR, IAAR and PNIF, rPNIF, IPNIF.

\begin{tabular}{|c|c|c|}
\hline \multicolumn{3}{|c|}{ Male and female subjects of the healthy group of study } \\
\hline & Correlation (r) & $p$-value \\
\hline PNIF vs AAR & -0.299 & 0.001 \\
\hline IPNIF vs IAAR & -0.373 & $<0.001$ \\
\hline rPNIF vs rAAR & -0.416 & $<0.001$ \\
\hline \multicolumn{3}{|c|}{ Male and female subjects of the pathologic group of study } \\
\hline & Correlation (r) & p - value \\
\hline PNIF vs AAR & -0.299 & 0.01 \\
\hline IPNIF vs IAAR & -0.462 & $<0.001$ \\
\hline rPNIF vs rAAR & -0.342 & 0.011 \\
\hline
\end{tabular}

While all subjects in the healthy group scored $<1$ on the SNOT 22 , in the pathologic one all volunteers, except 6 , had a mean SNOT 22 value $\geq 1(p<0.0001)$.

In the pathologic group, the nasal obstruction, assessed using the 22nd question of the SNOT22, (where the possible answers were: 0 no obstruction, 1 very mild obstruction, 2 mild obstruction, 3 moderate obstruction, 4 severe obstruction, 5 the worst possible obstruction), correlated both with PNIF ( $r=-0.28, p=$ $0.0017)$ and AAR $(r=0.22, p=0.013)$.
For total nasal patency, a ROC curve was calculated. The area under the curve measures jointly specificity and sensitivity of the fitted model, and comparing two predictive models, the one with a larger area is preferable. The area under the ROC curve was 0.682 ( $95 \% \mathrm{Cl} 0.590-0.775)$ if only PNIF was used and 0.676 $(95 \% \mathrm{Cl} 0.579-0.772)$ if only AAR was used, indicating a very similar and significant (although moderate) power to discriminate pathologic from healthy subjects (Figure 3). When, in addition to PNIF, age and height (both significant) were included in the logistic model, the area under the ROC curve was 0.762 (95\% $\mathrm{Cl} 0.678-0.846$ ) while if, in addition to AAR, height (the only significant covariate) was included in the logistic model, the area under ROC curve was 0.708 ( $95 \% \mathrm{Cl} 0.617$ - 0.799) showing a lower power to discriminate pathologic from healthy volunteers (Figure 4). The same analysis on rAAR, IAAR, rPNIF and IPNIF showed similar results (data not shown).

\section{Discussion}

Rhinomanometry is a well-established and safe method to assess nasal airway obstruction, but it is time-consuming, needs experience, is not easily transportable and the equipment is rather expensive.

The use of a reliable, cheap and simple method for assessing nasal airway obstruction is highly desirable and in the last few years a number of researchers have concentrated their work on PNIF with the purpose of defining normal values ${ }^{(10)}$.

Although Clarke and Jones in $1994{ }^{(17)}$ did not find an association between PNIF and RM, more than one study in literature 


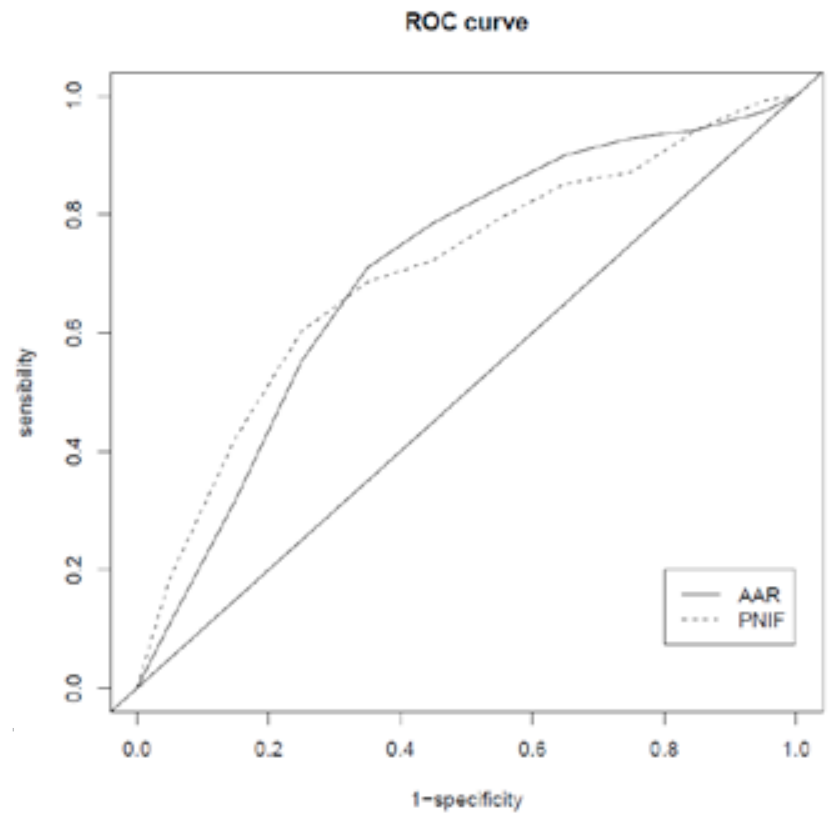

Figure 3. ROC curves for PNIF and AAR in males and females of both groups of study.

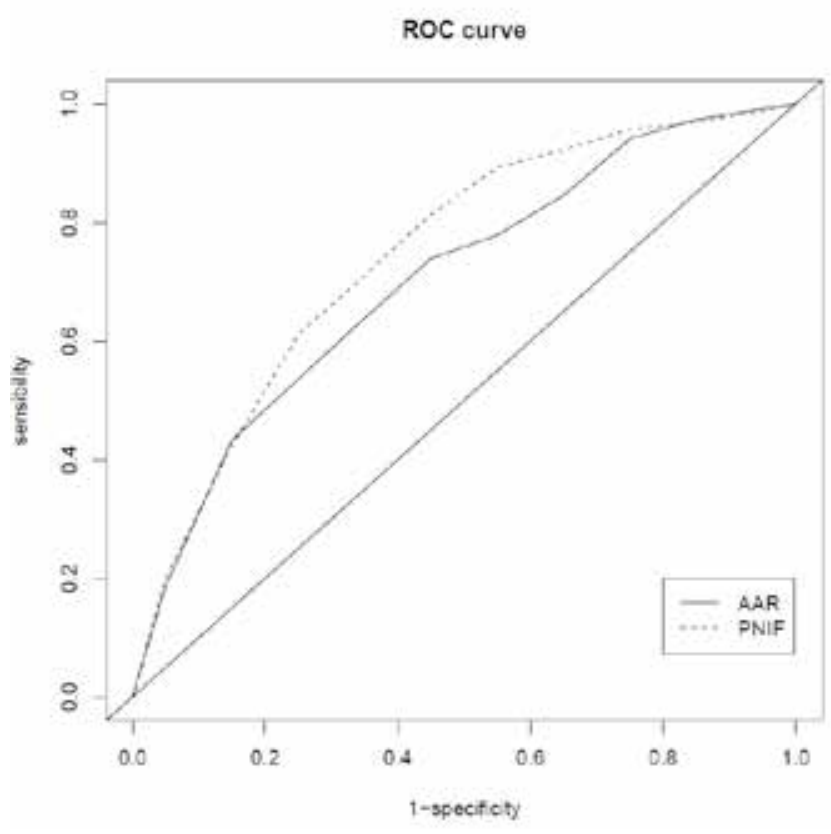

Figure 4. ROC curves for PNIF and AAR in males and females of both groups of study considering variables such as Age and Height. showed a good correlation between these two methods both in healthy and obstructed patients $(3,18-21)$.

In 2012, unilateral PNIF normal values were published ${ }^{(10)}$ allowing the use of the PNIF method to assess single nostril patency and to compare it with total nasal patency. The measurement of unilateral PNIF could become an easy way to assess nasal septal deviations or any case where there is suspicion of single nostril occlusion. To assess the validity of PNIF to measure various degrees of single nostril patency, in the present study, unilateral PNIF and unilateral nasal resistances were evaluated in healthy subjects and in patients with nasal obstruction.

Confirming previous results, PNIF and AAR demonstrated a reasonable correlation similar to the value reported in literature (3) both in healthy and pathologic populations, although PNIF still showed a large residual variability (Figures 1 and 2), similarly to that found in our previous experiences ${ }^{(6,7)}$. Furthermore, considering unilateral PNIF, we obtained a superimposable significant negative correlation between rPNIF, IPNIF and rAAR, IAAR, respectively, both in healthy and pathologic populations confirming the validity to study unilateral PNIF in rhinologic patients, in spite of the large residual variability similar to that found in a previous study ${ }^{(10)}$. Looking at Figure 1, for example, it is possible to observe that at IAAR value of $0.05 \mathrm{~Pa}^{*} \mathrm{sec} / \mathrm{ml}$ corresponds a wide range of IPNIF values. We maybe would have expected to obtain a higher degree of linear dependence between the two methods, but still the correlation found was significant and, given the fact that RM and PNIF assess different aspects of nasal airflow ${ }^{(22)}$, we believe that the correlation obtained in the present study should be considered acceptable.

The present study was not designed to evaluate the reproducibility of either PNIF or AAR as PNIF reproducibility as well as AAR reproducibility have already been demonstrated both in healthy and pathologic populations ${ }^{(23-26)}$.

Previous studies have demonstrated a correlation between subjective nasal obstruction and PNIF values ${ }^{(27-29)}$. The present study confirmed this correlation also showing that the SNOT22 score for nasal obstruction correlated better with PNIF than with nasal resistances studied by the mean of AAR. This result could lead to the hypothesis that PNIF might be slightly better than AAR in evaluating nasal obstruction in clinical practice.

The analysis of the diagnostic accuracy of PNIF and AAR in both groups of the study showed that each of the two methods are accurate in identifying pathologic patients. Interestingly, when considering the co-variates, age and height, PNIF was more accurate than AAR in identifying obstructed volunteers. Furthermore, the unilateral PNIF method has been shown to be as accurate as AAR in identify nasal obstruction, confirming once more that unilateral PNIF could be of utility to study nasal obstruction in those cases where there is suspicion of single nostril occlusion.

From this study, we conclude that PNIF could be a helpful method to support the diagnosis of functionally relevant nasal blockage also in those cases with single nostril obstruction, but, in cases of non accordance between patient's symptomatology 
and PNIF results or in all cases of doubt, AAR should also be performed to improve diagnostic accuracy.

\section{Authorship contribution}

GO: Study design, discussion of rhinological topics

VJL: Discussion of rhinological topics

EN: Data collection
BS: Statistical analysis

GF: Data collection

AS: Discussion of rhinological topics

GKS: Discussion of rhinological topics, supervision

\section{Conflict of interest}

None declared.

\section{References}

1. Corey JP, Houser SM, Ng BA. Nasal congestion: a review of its etiology, evaluation, and treatment. Ear Nose Throat J. 2000; 79: 690-693.

2. Clarke RW, Jones AS, Richardson H. Peak nasal flow- the plateau effect. J Laryngol Otol. 1995; 109: 399-402.

3. Holmström M, Scadding GK, Lund VJ, Darby YC. Assessment of nasal obstruction. A comparison between rhinomanometry and nasal inspiratory peak flow. Rhinology. 1990; 28: 191-196.

4. Holmstrom M. The use of objective measures in selecting patients for septal surgery. Rhinology. 2010; 48: 387-393.

5. Van Spronsen E, Ebbens FA, Fokkens WJ. Normal peak nasal inspiratory flow rate values in healthy children aged 6 to 11 years in the Netherlands. Rhinology. 2012; 50: 22-25.

6. Ottaviano G, Scadding GK, Coles S, Lund VJ. Peak nasal inspiratory flow. Normal range in adult population. Rhinology. 2006; 44: 32-35.

7. Ottaviano G, Lund VJ, Coles S, Staffieri A, Scadding GK. Does peak nasal inspiratory flow relate to peak expiratory flow? Rhinology. 2008; 46: 200-203.

8. Lund VJ. Diagnosis is not the end. Rhinology 2012; 50: 337-338.

9. Hellings PW, Scadding G, Alobid I, et al. Executive summary of European Task Force document on diagnostic tools in rhinology. Rhinology 2012; 50: 339-352.

10. Ottaviano G, Scadding GK, Scarpa B, Accord D, Staffieri A, Lund VJ. Unilateral peak nasa inspiratory flow, normal values in adult population. Rhinology. 2012; 50: 386-392.

11. Hopkins C, Gillett S, Slack R, Lund VJ, Browne JP. Psychometric validity of the 22-item Sinonasal Outcome Test. Clin Otolaryngol. 2009; 34: 447-454.

12. Ottaviano G, Marioni G, Staffieri C, et al. Effects of sulfurous, salty, bromic, iodic thermal water nasal irrigations in nonallergic chronic rhinosinusitis: a prospective, ran- domized, double-blind, clinical, and cytological study. Am J Otolaryngol. 2011; 32: 235-239.

13. Ottaviano G, Staffieri A, Stritoni P, et al. Nasal dysfunction induced by chlorinate water in competitive swimmers. Rhinology. 2012; 50: 294-298.

14. Vogt K, Jalowayski AA, Althaus W, et al. 4-Phase-Rhinomanometry (4PR)--basics and practice 2010. Rhinol Suppl. 2010; 21: 1-50.

15. Akaike H. A New Look at the Statistical Model Identification. IEEE transactions on automatic control. 1974; 19: 716-723

16. DeLong ER, DeLong DM, Clarke-Pearson DL. Comparing the areas under two or more correlated receiver operating characteristic curves: a nonparametric approach. Biometrics. 1988; 44: 837-845.

17. Clarke RW, Jones AS. The limitations of peak nasal flow measurement. Clin Otolaryngol Allied Sci. 1994; 19: 502-504.

18. Gleeson MJ, Youlten LJF, Shelton DM, Siodlak MZ, Eiser NM, Wengraf CL. Assessment of nasal airway patency: a comparation of four methods. Clin Otholaryngol. 1986; 11: 99-107.

19. Wihl JA, Malm L. Rhinomanometry and nasal peak expiratory and inspiratory flow rate. Ann Allergy. 1988; 61: 50-55.

20. Viani L, Jones AS, Clarke R. Nasal airflow in inspiration and expiration. J Laryngol Otol. 1990; 104: 473-476.

21. Jones AS, Viani L, Phillips DE, Charters P. The objective assessment of nasal patency. Clin. Otolaryngol. 1991; 16: 206-211.

22. Bermüller $C$, Kirsche $H$, Rettinger $G$ Riechelmann $\mathrm{H}$. Diagnostic accuracy of peak nasal inspiratory flow and rhinomanometry in functional rhinosurgery. Laryngoscope. 2008; 118: 605-610.

23. Klossek JM, Lebreton JP, Delagranda A, Dufour X. PNIF measurement in a healthy French population. A prospective study about 234 patients. Rhinology. 2009; 47: 389-392.

24. Starling-Schwanz R, Peake HL, Salome CM et al. Repeatability of peak nasal inspiratory flow measurements and utility for assessing the severity of rhinitis. Allergy. 2005; 60: 795-800.

25. Silkoff PE, Chakravorty S, Chapnik J, Cole P, Zamel N. Reproducibility of acoustic rhinometry and rhinomanometry in normal subjects. Am J Rhinol. 1999; 13: 131-135.

26. Shelton DM, Pertuze J, Gleeson MJ, et al. Comparison of oscillation with three other methods for measuring nasal airways resistance. Respir Med. 1990; 84: 101-106.

27. Fairle JW, Durham LH, Ell SR. Correlation of subjective sensation of nasal patency with nasal inspiratory peak flow rate. Clin Otolaryngol Allied Sci. 1993; 18: 19-22.

28. Hox V, Bobic S, Callebaux I, Jorissen M, Hellings PW. Nasal obstruction and smell impairment in nasal polyp disease: correlation between objective and subjective parameters. Rhinology. 2010; 48: 426-432.

29. Yepes-Nuñez JJ, Bartra J, Muñoz-Cano R, et al. Assessment of nasal obstruction: Correlation between subjective and objective techniques. Allergol Immunopathol. 2012; doi: 10.1016/j.aller.2012.05.010. [Epub ahead of print].

Giancarlo Ottaviano, MD, PhD

Department of Neurosciences

Otolaryngology Section

University of Padova

Via Giustiniani 2

35128 Padova

Italy

Tel: +39-(0)49-821 2029

Fax: +39-(0)49-8213113

E-mail: giancarlo.ottaviano@unipd.it 